\title{
Interactive Design and Significance of College Mathematics Classroom Teaching In China
}

\section{Zhizhen Wang \\ Department of Mathematics, Shanghai Normal University, Shanghai, China}

Email address:

wzhzh@shnu.edu.cn

\section{To cite this article:}

Zhizhen Wang. Interactive Design and Significance of College Mathematics Classroom Teaching In China. Education Journal. Vol. 4, No. 5, 2015, pp. 312-314. doi: 10.11648/j.edu.20150405.30

Abstract: This paper mainly analyzes the significance and feasibility of interactive teaching in teaching mathematics in chinese higher education. In the face of the current difficulties in higher education, interactive teaching provides us with a means of operation.

Keywords: Mathematics Education, Classroom Interaction, Higher Education

\section{中国高校数学课堂教学中互动设计与意义}

\section{王志珍}

数学系, 上海师范大学, 上海, 中国

邮箱

wzhzh@shnu.edu.cn

摘要：本文主要分析了国内高等教育中, 数学课堂教学中的互动教学的意义和可行性。在面临当下高等教育的种种困 境中, 互动教学提供给我们一个可操作的手段。

关键词: 数学教育, 课堂互动, 高等教育

\section{1. 引言}

现代教育是依托课堂教学来完成的。在现代教学理 论中, 课堂教学过程被认定为一种特殊的认识过程, 是 师生双方作为主体以共同的客体为中介完成的交往过程。 既然教学过程是根据一定的社会要求, 结合学生的身心 特点, 设定一定教学目的, 由教师和学生共同完成的双 边活动, 那么教师、学生、教学内容和教学手段就构成 了教学过程的基本要素。调动整合这些要素就是顺利完 成教学的关键之处。教学互动在这一点上抓住了处理问 题的要素。因此在现在的课堂教学中, 教学互动是非常 重要的环节。这种教学组织形式需要师生互相交流、共 同探讨来完成学习过程。

\section{2. 课堂互动}

课堂互动教学在中小学教师授课中被普遍认可, 并且 是精心设计的部分。在高等教育中, 教学侧重于知识的传 授, 学生也有较好的自学能力, 因此在教学互动环节投入 较少。但是现代教育全民化、普及化, 接受高等教育的学 生受众面很广, 程度差异很大。同时, 现代媒介手段如此 发达, 电子产品对人的影响如此深刻, 使得现代课堂教育 面临很大的考验。我们需要与手机、资讯、社交软件争夺 学生的心思。这是一个事实的, 也是一个全球性的现象。 在新的教育形势下, 如何有效的实施教学, 合理设定教育 目标, 就是一个有时代特点的现实性问题。当然, 教育是 
一项复杂的工程, 没有一劳永逸的万能手段。但是, 教学 互动对于很多教学中的问题依然是有效的。

\section{1. 课堂互动的意义和局限}

教学互动的内容主要包含互教互学, 交流广泛的信息 面和共同参与、创造性的实现教学目标。在实际教学中, 要处理好这三方面的内容和课堂教学的关系很重要。互教 互学的一种具体做法就是学习互换: 学生预习备课, 在学 生讲解课程的过程中, 由教师提问、讨论来完成知识学习。 但是在目前的本科教学中, 教学班级人数经常很多, 有些 稍微少点, 但是整体来说, 班级人数都比较多。这种情况 下, 此类教学方法就不太适用了。特别是学生水平参差不 齐时, 要调动全部学生参与到这种学校教学活动中, 就更 有难度了。有时候, 交流的信息面较广、师生共同参与时, 就会流于表面, 话题放开后收不拢。课堂互动对于教学是 有积极正面的意义。但是课堂授课时间有限, 如何平衡和 处理好课堂互动的程度和内容, 是值得细细思量的问题。 围绕设定的话题和任务, 形散而神聚地完成讨论和交流是 一个非常有挑战的工作。在这一点上, 有人建议多问几个 有没有: 有没有突破? 有没有延伸出新问题? 有没有发展 学生的个性思维? 有没有促进教师的进一步思考?

\section{2. 数学教育中的课堂互动}

而在公共数学教学设计中, 互动教学的困难就更具体 了。因为学科的特点, 数学类课程历来让学生发怵。很多 学生畏惧数学, 实在是从小养成的心理习惯使然。在本科 教学课堂中, 学生数学基础和数学思维差异极大。这对于 互动教学来说, 既是挑战也是机遇。教师可以通过互动教 学环节, 了解和把握学生状况, 从而适当调整教学目标与 教学进度。另一方面, 在学生的学习积极性较低的情况下, 让学生参与到主动学习中, 这涉及的心理疏导已经超出课 堂教学所能施展作用的范围了。这使得在公共数学课程中, 有效开展互动教学是一件颇有难度的事情。

在课堂教学中, 互动发生的方式基本体现在课堂中的 问答环节。如何实现问答环节是课堂教学的枢纽所在。传 统课堂教学中, 互动是为了讲解知识点, 是学生更好地了 解课堂教学的内容, 同时也使教师能即时地了解学生的学 习情况。有时候, 这种教学互动也是为了督促学生第一时 间练习所讲授学习的知识, 并在这个过程中发现具体问题。 但是除了课堂互动对于知识点本身的讲授意义以外, 课堂 互动对于建构良好的课堂氛围, 形成和谐的课堂沟通渠道 也有着至关重要的意义。尤其是理科专业, 在讲授严谨详 实的概念和大量的公式推导中, 若能够在讲授过程中, 充 分发挥课堂互动的作用, 设计更多的课堂互动的细节, 将 非常有助于顺利地实现相关知识的授课目标。

目前本科阶段, 数学课程的基本特点是教师讲, 学生 记笔记, 课堂做练习, 课后做习题。虽然有提出课前预习 的要求, 但在实际学习过程中, 学生基本没有完成这一点。 传统的数学课, 讲完一堂课, 笔记一叠厚, 学生直呼难。 高等教育普及的今天, 课程改革也很注意时代的变化, 在 难度、广度和力度几个方面均有较大变化; 分层教学更加 普遍了。在公共数学课程中, 考虑到学生程度和专业的一
般需要, 课程也相应分层。有的按上课时数划分, 有的按 类型划分。但是, 无论怎样划分, 同一层内的学生差异仍 是存在的, 并且不可忽视的。因此在相应的课堂教学中, 若能针对学生特点, 设计和利用互动教学环节, 则更有助 于实现教学目标。这也更能体现数学教学是师生之间交往 互动与共同发展的过程。

\section{3. 数学课堂互动情况分析}

鉴于数学学科及教育现状, 在公共数学互动教学中, 如何设计和实践互动环节更是一个有挑战性的问题。在阐 述这个问题之前, 我们要有一点共识, 互动意味着相互学 习, 但是教师是其中的主导者。因此一方面要有平等心, 能静得下心来, 坐下来仔细倾听感受学生的思想和观点; 另一方面, 教师又要有一个预设的目标, 完成相应阶段的 教学任务。课堂互动的内容和环节可以穿插分散到教学中 各个节点中, 可以以运算、口答、重述和情景设计等多种 方式来实现。在实践中, 我们可以在复习、概念讲解、习 题分析几个阶段中分散实施互动教学。通过复习阶段的互 动问答, 在复习前一次课程内容的基础上, 也对学生掌握 情况有所了解。在课堂中间, 设置一定的互动环节, 针对 重要概念和知识点, 在讨论交流中完成学习, 可以有效的 控班, 让同学们关注到课堂。事实上, 现在的大学课堂上, 手机是一个影子学生, 无时不出现在课堂中。有些学生用 它辅助学习, 比如拍课件, 存储知识要点, 查找信息等等。 但相当一部分学生是在使用手机的游戏、小说、社交等功 能。因此在课堂教学中, 一方面要有规则, 有限制的使用 手机; 一方面要调动学生的积极性, 使之参与到课堂教学 活动中。在实践教学中, 限制使用手机, 可以使师生双方 有一个相处的依据。具体实施中, 可以提出手机不能放在 桌面上等要求。有些学生依赖成习惯, 基本不能自控。这 时候, 一定的课堂互动问答将是一种有效的督促手段, 使 之重新投注心力到课堂中。对于程度较好的同学, 也可以 通过问答, 分析演示学生对课堂知识可能的理解偏差。习 题分析中的互动更有意义。在这个过程中, 可以针对学生 出现的具体错误, 分析背后的知识点和分析方法, 同时也 可以交流分享新的思想方法和解题思路。

\section{4. 数学课堂互动的准则和实例分析}

在课堂互动中, 采用生活中的语言、案例加以分析, 并设置相关问题, 在课堂中加以讨论。在实践中, 实施课 堂互动中有以下体会:

一、语言要简单, 有时代性;

二、方式要灵活, 态度要包容;

三、教师要有主导权, 把握课程节奏。

在这里, 我们用一个具体课堂互动实例来说明这些。 工程数学是许多工科专业的必修专业课。该课程的基本教 学目标是让学生学习线性代数、概率等的基本知识和基本 方法, 使学生打下坚实的数学基础, 掌握牢固的数学知识, 提高学生的抽象思维能力、逻辑推理能力、实际应用能力 以及解题的技能与技巧, 并为进一步学习后继课程及相关 课程打好基础。在这个学习过程中, 矩阵是同学们需要掌 握的一个概念。这是线性代数中的最基础的概念之一。但 
是学生们对此概念的理解和掌握却常常不尽人意。在形式 上, 矩阵和行列式有相似之处, 有相当一部分同学在这两 者上无法正确区分和运算。我们考虑在授课中, 设计互动 环节, 以强调矩阵是存储信息的表格这一本质特征, 请同 学们举例说明生活学习中的矩阵表格, 如考勤记录, 个人 财务记录等等。此外, 还可以做情景角色演练。让同学们 设想, 自己作为一个商店店主, 在产品采购、销售环节中, 记录数据, 存储数据。存储的数据有多种形式, 不同用途, 如何处理数据, 综合数据, 分析数据。在这些环节中, 矩 阵的基本运算就自然地导入了。

当然, 数学课堂的互动设计可以有许多形式, 结合其 他教学新思维, 我们可以设计课题式作业, 可以小组式学 习, 圆桌式讨论等等。

\section{3. 结束语}

本文从一线高等教育的课堂观察出发, 针对高等教育 中的数学课堂教学提出了一点看法。当下高等教育面临着 众多的挑战, 如何化解和看待当下的种种教育问题, 是我 们的任务。从细节入手, 但又不局限与眼前, 方有可能对 这些教育难题给出一个可行的方案。

\section{参考文献}

[1] 张德祥, 论高等教育的和谐发展与和谐社会建设 [J].中国 高教研究, 2007, 11: 3-8。
[2] 文菊, 姚利民, 高等教育大众化背景下提高高校教学质量 的对策初探 $[\mathrm{J}]$. 高等教育研究学报, 2005, 4: 87-90。

[3] 丁虹, 王吟, 李美蓉, 关于对高等数学教学改革的若干思 考与建议 $[J]$. 合肥师范学院学报, 2010，6：10-12。

[4] 胡洪伟, 课堂师生交往及其策略研究 [D]. 华东师范大学硕 士学位论文, 2003。

[5] 程晓樵, 教师在课堂互动中的策略 [J]. 教育评论, 2001, 4: $4-7$ 。

[6] 廖坤慧, 教师提问策略对课堂师生互动的影响 [D]. 四川大 学硕士学位论文, 2006。

[7] 刘尧, 戴海燕, 课堂师生互动研究述评 [J]. 教育科学, 2010, 6: 66-69。

[8] 刘静, 九十年代以来我国师生关系研究述评 $[\mathrm{J}]$. 现代教育 论从, 2003, 3: 9-15。

[9] 孙发利, 苏保卫, 师生互动教学的策略问题 [J]. 延安教育 学院学报, 2003, 17: 7-8。

[10] 王亚维, 教师如何组织课堂教学活动 $[\mathrm{J}]$. 时代教育 (教育教 学), 2012年10期。

[11] 陈少国, 基于有效教学的课堂互动策略 $[\mathrm{J}]$. 教学与管理, 2013，5：17-19。

[12] 蒋延文, 庞莉, 临床医学教学中课堂互动的策略 $[J]$. 中国 医学创新, 2013，28：139-141。 